\title{
ARTIGOS
}

Submetido 12.02.2014. Aprovado 30.03.2015

Avaliado pelo processo de double blind review. Editora Científica: Marlei Pozzebon

DOI: http://dx.doi.org/10.1590/So034-759020150603

\section{GRUPO DE DISCUSSÃO COMO PRÁTICA DE PESQUISA EM ESTUDOS ORGANIZACIONAIS}

\author{
Discussion group as research practice in organizational studies \\ Grupo de discusión como práctica de investigación en estudios \\ organizacionales
}

\begin{abstract}
RESUMO
O objetivo deste ensaio teórico-metodológico reside em apresentar e discutir a metodologia do Grupo de Discussão (GD) como prática grupal de pesquisa qualitativa, abrindo possibilidades posteriores para utilização no campo dos estudos organizacionais. Estruturam-se as seguintes etapas: alerta sobre o equívoco do entendimento da prática de GD como receituário; descrição sobre o que é GD e discurso grupal; diferenciação entre GD e focus group; discussão sobre os elementos técnicos do GD. Espera-se contribuir para a apresentação dessa metodologia aos pesquisadores do campo dos estudos organizacionais e para o desenvolvimento do lugar do grupal nas práticas de pesquisa social.
\end{abstract}

PALAVRAS-CHAVE | Grupo de discussão, técnicas de pesquisa, práticas de grupo, pesquisa qualitativa, metodologia.

\begin{abstract}
The goal of this theoretical-methodological essay is to present and discuss the methodology of Discussion Group (DG) as a group practice in qualitative research, opening further possibilities to apply it in organizational studies. The essay is structured as follows: first, we present a warning about the misconception involving the practice of DG as a prescription; second, we describe DG and group discourse; then we differentiate DG and focus group; finally, we discuss the technical elements of DG. This essay contributes to present this methodology to researchers of organizational studies and to develop the place of group practices in social research.
\end{abstract}

KEYWORDS I Discussion group, research techniques, group practices, qualitative research, methodology.

\section{RESUMEN}

El objetivo de este ensayo teórico metodológico reside en presentar y discutir la metodología del Grupo de Discusión (GD) como práctica grupal de investigación cualitativa, abriendo posibilidades posteriores para utilización en el campo de los estudios organizacionales. Se estructuran las siguientes etapas: alerta sobre el equívoco del entendimiento de la práctica de GD como recetario; descripción sobre lo que es GD y discurso grupal; diferenciación entre GD y focus group; discusión sobre los elementos técnicos del GD. Se espera contribuir a la presentación de esa metodología con los investigadores del campo de los estudios organizacionales y para el desarrollo del lugar de lo grupal en las prácticas de investigación social.

PALABRAS CLAVE / Grupo de discusión, técnicas de investigación, prácticas de grupo, investigación cualitativa, metodología. 


\section{INTRODUÇÃO}

A relevância do grupo como instrumento de investigação utilizado em diversas disciplinas como antropologia, sociologia, psicologia social, psicanálise, saúde, educação, políticas públicas, comunicação e marketing, nos remete historicamente aos experimentos de Elton Mayo, no início dos anos 1930. A partir da segunda metade dos anos 1940, entram em cena o enfoque psicodramático de Lewin, e Moreno e o grupo de encontro postulado por Rogers. Posteriormente, a psicanálise, com Bion, Winnicott, e Anzieu, também teve uma influência grande no estudo dos grupos e das técnicas grupais (Gutiérrez, 2008, 2009, 2011; Lapassade, 1989). A partir desses exemplos de experimentos, investigações e autores, o grupo passou a ser um elemento-chave para a pesquisa social.

A compreensão sobre a utilidade do grupo passou por uma evolução e diferenciação em virtude de diversas abordagens originárias de âmbitos distintos. Dessa forma, diferentes nomes são usados para referir-se a um mesmo tipo formal de grupo; entre eles, o focus group, de origem anglosaxã, é o mais conhecido. A obra que popularizou a técnica nos âmbitos da pesquisa social e de mercado foi o texto clássico de 1956, The focused interview, de Merton, Fiske, e Kendall (1990). Por outro lado, o termo Grupo de Discussão (GD) - tema deste ensaio - remete-se a uma técnica posterior que tem suas origens na Espanha a partir dos anos 1970.

As origens do GD na Espanha estão ligadas ao contexto da história política do país e aos nomes da sociologia crítica de Jesús Ibánez, Alfonso Ortí, Ángel de Lucas, Francisco Pereña e José Luiz Zárraga, assim como aos trabalhos mais recentes de investigadores formados por eles (Callejo, 2001, 2002a; Domínguez \& Davila, 2008; Gutiérrez, 2011). No momento histórico de surgimento do GD, a sociologia espanhola estava predominantemente identificada com as práticas quantitativas da pesquisa de opinião, utilizando questionário (encuesta). 0 GD surge, então, como algo inteiramente novo, contrário ao formalismo instrumental da sociologia empírica e, como narra Callejo (2001), foi construído com os materiais críticos do momento: estruturalismo, psicanálise e Escola Crítica de Frankfurt. Em torno do GD, se estabelece uma boa parte da fundamentação metodológica dos partidários dos métodos qualitativos na Espanha (Lucas \& Ortí, 1995 como citado em Callejo, 2001).

Ibánez, Ortí, e Lucas, fundadores também da chamada “Escola Crítica Qualitativista Madrilena” (Godoi \& Coelho, 2011) refundaram teoricamente $\mathrm{oGD}$, iniciando sua prática na realização de estudos de mercado. Como recordam Sánchez-Pinilla e Legerén (2008), nos primeiros momentos, a prática do GD aproximava-se muito de um grupo terapêutico, e o papel de moderador e intérprete dos fenômenos produzidos na microssituação do grupo era atribuição prioritariamente de um psicanalista (Anzieu, 1986). No entanto, essa proximidade e semelhança ao grupo terapêutico logo foi abandonada e o centro da análise passou a ser a macro situação social dos participantes do grupo, sendo a figura do psicanalista substituída pela do investigador em ciências sociais.

Com relação à tradução sistemática, ocorrida em diversos países, de focus group por GD, gerando uma confusa compreensão dessas práticas, Gutiérrez (2008) é um dos autores que alertam que suas inúmeras diferenças epistemológicas e técnicas não podem ser reduzidas a questões linguísticas ou regionais que pouco afetam seu conteúdo. O GD costuma ser popularmente considerado de maneira reducionista, uma versão mais flexível, aberta e menos diretiva de focus group. Entretanto, o aprofundamento metodológico e a observação prática da utilização da técnica conduzem à compreensão da diversidade de suas diferenças, ainda que se reconheçam suas semelhanças aparentes. Iniciamos por dizer que o GD, de origem hispano-americana, teve seu aparecimento posterior e desenvolveu-se, como concorda Gutiérrez $(2008,2011)$, com uma sólida justificação teórica e identidade própria que o focus group, com marcado caráter positivista, não chegou a ter no âmbito anglo-saxão.

O GD não permaneceu reduzido à pesquisa de mercado, mas atraiu o interesse de pesquisas de diferentes campos das ciências sociais e humanas. Entretanto, não se tem conhecimento do uso dessa forma particular de técnica grupal no campo dos estudos organizacionais. Da mesma forma, o GD passou a ser utilizado em diferentes países da Europa e América Latina, porém, no Brasil, o conhecimento acerca dessa prática entre as diferentes disciplinas do conhecimento ainda é bastante incipiente. Portanto, o objetivo deste ensaio reside em apresentar e discutir a metodologia do GD como prática grupal de pesquisa qualitativa, abrindo possibilidades posteriores para utilização no campo dos estudos organizacionais.

O ensaio teórico-metodológico está estruturado nas seguintes etapas: a) um alerta sobre o equívoco do entendimento da prática de GD como um receituário de procedimentos técnicos; b) descrição sobre a noção conceitual de GD e de discurso grupal; c) diferenciação detalhada entre GD e focus group; d) explanação sobre os diferentes elementos metodológico-técnicos do GD, tais como o desenho e a formação do grupo, o papel do moderador e a dinâmica do GD. Espera-se contribuir para a apresentação dessa metodologia aos investigadores do campo dos estudos organizacionais que ainda não a conheçam, bem como para o desenvolvimento do lugar do grupal nas práticas de pesquisa social. 


\section{ENTRE $O$ RECEITUÁRIO E 0 AMADORISMO: A APLICAÇÃO DINÂMICA DA TÉCNICA}

Callejo (2001) é um dos autores que alertam enfaticamente para o fato de que, ao pretender enfrentar-se um GD, é conveniente ter presenciado, como observador, reuniões conduzidas por algum especialista. Os principais mentores dessa metodologia acreditam que sua aprendizagem se dá principalmente por meio da experiência prática.

A autora escreveu o artigo por ocasião da realização de seu Estágio Pós-Doutoral Sênior (CAPES - 2012-2013) no departamento de Métodos de Investigación y Teoría de la Comunicación - Sociologia IV (na Universidad Complutense de Madrid [UCM]) - centro de origem da maior parte dos métodos da pesquisa social qualitativa espanhola. 0 pós-doutorado na UCM foi sobre o Método da Análise Sociológica do Discurso e a história da pesquisa qualitativa naquele país. Durante o ano de permanência no departamento, a técnica de GD (que, no projeto inicial, se reduzia a um objetivo específico) assumiu maior relevância, considerando ser esta a principal prática de coleta de dados a serem submetidos à análise do discurso (Godoi, Coelho \& Serrano, 2014), típica dos sociólogos do país.

Passou, então, a pesquisadora a participar tanto do departamento de Sociologia IV da UCM como professora convidada quanto a buscar a oportunidade de trabalhar como pesquisadora assistente/observadora do CIMOP - Comunicación, Imagen y Opinión Pública - centro de pesquisa social e de mercado, dirigido por ex-catedráticos da Universidad Complutense, autores de manuais sobre GD e ASD, tais como Fernando Conde Gutiérrez de Álamo e Cristina Santamarina. O CIMOP é considerado o principal centro de prática de pesquisa social e de mercado na Espanha. Todas as reuniões do grupo (12 grupos) foram realizadas no interior do instituto, preparadas com mesas redondas em sala de espelho, salas de observação e filmadora. Após as reuniões, a pesquisadora discutia questões técnicas com os moderadores/pesquisadores do centro. Além das observações diretas, foram disponibilizados à pesquisadora inúmeros vídeos pertencentes ao arquivo do instituto (a maior parte sobre os problemas de gênero e da imigração - temas sociais prioritários na Espanha; alguns desses vídeos estão referenciados).

Retornando ao risco de receituário, da mesma forma que os demais métodos de pesquisa qualitativa, o GD não é considerado, ainda que por vezes possa transparecer neste ensaio, um conjunto de técnicas e procedimentos, mas sim uma prática de pesquisa (Callejo, 2001; Canales \& Peinado, 1994; Gutiérrez, 2008; 2009). Gutiérrez (2009) explica essa distinção ao salientar que as técnicas são práticas grupais porque sua formulação e colocação em funcionamento dependem da situação concreta onde se aplicam e dos propósitos concretos. 0 pesquisador, portanto, “ocupa a técnica” e reflete sobre ela (Canales \& Peinado, 1994). O que aqui se pretende, ao sistematizar sobre o sentido da aplicação da técnica, por meio de seus autores, tanto precursores quanto contemporâneos, não reside em entender o GD como receituário, manual, protocolo ou conjunto de procedimentos a serem aplicados cegamente e de modo independente do contexto particular, mas sim considerá-lo como prática dinamizadora na qual todo o aparato técnico se adapta e está condicionado à situação concreta de investigação (Gutiérrez, 2008; Ortí, 1986). Um dos conhecidos dizeres de Ibánez, alerta que o GD não está sustentado por procedimentos e que não se trata de prescrever como se faz tal coisa, mas sim as consequências, ou seja, ao fazer tal coisa, pode ocorrer outra.

Ainda que o pesquisador não conte com regras nem receitas padronizadas de aplicação mecânica, inflexível e fixa, isso não elimina, no entender de Ortí (1986), certa habilidade para manter sob controle o teatro que o grupo reproduz. Isso significa que, ainda que o GD constitua uma "práxis artesanal", o pesquisador não pode prescindir de um saber fazer, pensado e sistemático, que assegure a sua realização (Gutiérrez, 1999, 2008). Inclusive porque, ao cair no oposto do receituário, entrar-se-ia na aplicação despreocupada, ingênua e acrítica condutora da confusão conceitual e empírica entre as distintas técnicas grupais.

Esses riscos, quer de formalismo, quer de anarquia, na prática do GD - problema também inerente a outros métodos de pesquisa qualitativa - evidenciam e trazem à tona outra grande dificuldade que têm a pesquisa e o ensino do GD: a dificuldade de mostrar e ensinar a técnica. Por esse motivo, ainda que conscientes de que a prática do GD deva superar a aplicação mecânica da técnica, não se pode prescindir de iniciar a sua discussão também em todas as suas peculiaridades técnicas. Isso significa que o formalismo, por si só, engessa a pesquisa qualitativa; acreditamos, por outro lado, que textos metodológicos inaugurais de práticas inovadoras no país no campo científico em que se está trabalhando - permeadas de uma experiência do pesquisador - podem ser motivadoras a pesquisadores iniciantes. Cabe, portanto, ressaltar que a motivação deste ensaio emergiu quando a autora sentiu necessidade de elaborar uma narrativa completa de seus estudos em obras, artigos e relatórios de pesquisa - material que, em grande parte, não teria acesso estando no Brasil, com dupla finalidade: nortear a prática de pesquisadores e estudantes interessados e em fase de entrada no campo, apresentar aos pesquisadores e professores brasileiros de metodologia uma nova possibilidade de prática de pesquisa qualitativa, desvinculada da epistemologia neopositivista como o grupo focal. 


\section{O QUE É 0 GRUPO DE DISCUSSÃO: 0 DISCURSO GRUPAL}

Introduzindo a compreensão conceitual dessa prática grupal de pesquisa qualitativa, bem como de que consiste o discurso grupal, Alonso (1998) descreve de maneira simples que o GD é um grupo artificial, convocado em função dos objetivos da pesquisa e controlado pelo pesquisador. Noutros termos, a finalidade do grupo reside em recuperar a participação ativa do sujeito na pesquisa, outorgando-se a liberdade para expressar sua opinião sobre o sentido de suas ações relacionadas à sua vida cotidiana (Manrique \& Pineda, 2009).

É fundamental ressaltar que, em realidade, o GD não constitui a priori um grupo, pois trata-se de um "processo de reagrupação” (Callejo, 2001; Ibáñez, 2003). Explicando, poderíamos dizer que o movimento de desenrolar do grupo se dá entre o incentivo à reagrupação e o impedimento de que o grupo chegue a consolidar-se. Tal processo acontece, na narrativa de Ibáñez (2003), em três níveis: a) integração pessoal, que se refere à busca da integração do sujeito no grupo; b) integração social, que trata da busca da posição do sujeito e c) integração sistêmica, que consiste na busca da integração do grupo no sistema.

Para entender o significado do discurso grupal, iniciamos por tomar as palavras de Alonso (1998, p. 101): “o grupo constitui um dispositivo de produção de textos, que serve de suporte a discursos e representações sociais". Essa sutil distinção entre texto - produzido no diálogo grupal - e discurso aparece também em Callejo (2001), ao considerar que o grupo, em sua gênese e produção, é um diálogo, porém, em seu resultado, é um discurso. Tal distinção desses dois momentos encontra sentido ao considerarmos que o discurso é uma construção do analista realizada a partir da análise das condições de produção do discurso. Entretanto, na concepção condensada de Ibáñez (2003), o grupo em si já consiste em uma "máquina de produção de discurso".

Com a finalidade de garantir o diálogo entre os participantes, há duas questões que se impõem como fundamentais: a homogeneidade e a simetria. No entender de Sánchez-Pinilla e Legerén (2008), a simetria evita que apareçam relações de dominação existentes no espaço social e que poderiam impedir a existência do grupo como tal. Conceito semelhante, que contribui para a circulação de discursos é o da homogeneidade social (Callejo, 2002a) entre os participantes.

Outra questão relevante ao entendimento do GD e sua organização particular de sentido é justamente a necessidade de compreendê-lo como um lócus de produção de sentidos coletivos originários e incorporados na trajetória social dos indivíduos. Dessa forma, ainda que o grupo seja considerado como um todo, e não como um somatório de indivíduos, Ibáñez (2003) alerta que se trata no grupo de uma unidade mínima de interação social e, como tal, reproduz uma ordem social.

Por esse motivo, ideologia, contradição e conflito são termos que atravessam as obras, textos e relatórios de investigação dos precursores do GD, bem como a observação de suas práticas de condução de grupo. Isso porque, na relação dialética que surge entre o investigar/moderador e o grupo, o discurso adquire seu sentido e possibilita a revelação do sistema ideológico subjacente, explica Ortí (1986). Um GD é um dispositivo de análise que depende do processo de "colocação em colisão” (Ibáñez, 2010) de diferentes discursos sociais, ou seja, algum conflito de natureza ideológica ou inerente aos tipos sociais que os membros representam. Trata-se de uma técnica na qual os conflitos sociais têm lugar privilegiado e, por esse motivo, é capaz de captar a dimensão incoerente do discurso.

Para finalizar este breve capítulo sobre a concepção do GD, cabe ainda explicar que, na obra de Ibáñez encontram-se, simultaneamente, dois registros, o sociológico e o psicanalítico. 0 primeiro refere-se aos modelos socioculturais de interação social e à experiência prática de pesquisa do autor, e o segundo é utilizado por ele na tentativa de legitimar metodologicamente a técnica. Portanto, em suas origens, o GD foi construído na articulação entre o campo social e libidinal (Criado, 1997; Sánchez-Pinilla \& Legerén, 2008).

\section{DIFERENCIANDO GRUPO DE DISCUSSÃO E FOCUS GROUP}

Entrevista de grupo, grupo focalizado, enfocado, grupos nominais, grupo de peritos, grupos delphi, minigrupos, grupos triangulares (Conde, 2008) e GD formam um catálogo diverso de nomenclaturas utilizadas para técnicas grupais aparentemente semelhantes. O problema, no entanto, começa no momento em que as traduções do inglês ou do francês ao espanhol e ao português, por exemplo, começaram a considerar como sinônimos focus group, entrevistas profundas em grupo (group depth interview) e grupo de discussão, tal como denuncia Callejo (2001).

Do ponto de vista da técnica e da ferramenta, ou seja, da aparência formal, GD e focus group mantêm semelhanças entre si. Na síntese elaborada por Gutiérrez (2011), ambas servem para produzir e registrar discurso grupal. Cabe aqui observar nossa discordância de que o grupo focal possa produzir discurso, mas sim opiniões segmentadas. No entanto, a semelhança entre essas técnicas não ultrapassa o plano formal e, portanto, não atinge o plano prático, tal como abordaremos neste capítulo, buscando 
analisar diferenças nas concepções teóricas, técnicas, metodológicas e epistemológicas.

Sobre as origens de ambas as técnicas, atentamo-nos principalmente sobre a leitura de Morgan (1996) para concluir que o focus group, originariamente chamado de entrevista em grupo ou entrevista profunda em grupo, resultou de uma adaptação na maneira de aplicar a entrevista individual, com finalidade de facilitação na rápida obtenção de informação. Com uma gênese totalmente distinta, tal como já descrevemos, o GD emerge num contexto de mercado e de consumo, com uma postura epistemológica crítica ao enfoque quantitativo predominante na época e influenciado pelo grupo terapêutico e pela psicanálise.

Ainda que posteriormente se tenha estabelecido modificação, distanciamento e autonomia do GD em relação ao grupo terapêutico e à psicanálise, faz-se necessário caracterizar melhor esses dois momentos, o do mimetismo inicial e o da independência, utilizando a explicação de Gutiérrez (2011): em seus primeiros momentos, o GD atribuía à figura de um psicanalista os papéis de moderador da dinâmica e de intérprete dos fenômenos produzidos na microssituação do grupo; em seguida, com o abandono dessa dependência, a prática do GD passou a dedicar-se aos fenômenos macros situacionais e interpretados de acordo com os objetivos da pesquisa.

Uma das questões práticas mais relevantes e que se faz necessária para compreender a diferenciação entre GD e focus group é o tema do consenso. Na explanação de Gutiérrez (2011), o GD utiliza a cooperação dos participantes de modo que - a partir de discussões, matizes, silêncios, ecos da fala - o grupo consiga atingir, ao final, o consenso sobre os objetivos da investigação. O consenso, portanto, é o horizonte do GD. Nossa experiência de observação direta, no entanto, nos leva a crer não ser o consenso uma tarefa fácil, mas sim incerta e que, de alguma forma, preocupa o investigador durante a condução da sessão. Em oposição, o focus group não visa o consenso final, mas sim parte inicialmente de um consenso, ou seja, de uma compreensão e definição sobre o objeto já dada pelo moderador, que durante o processo grupal trata de recolher opiniões e informações sobre esse fato. É com relação ao consenso o conhecido dizer de Ibáñez (2003, p. 267) de que "o GD acaba onde o FG começa".

Enquanto no GD assistimos à predominância do intercâmbio dialógico que dá sentido ao discurso grupal, no focus group o que predomina é o produto verbal, o dado, que é então reconhecido tecnicamente. O GD extrai discursos; o focus group coleta dados (Gutiérrez, 2008, 2011; Morgan, 1996). Essa ênfase na circulação de discursos como tendo valor máximo como representação do grupo assinala uma das principais diferenças do GD em relação a outras técnicas grupais (Callejo, 2002b). Acerca ainda da noção de intercâmbio dialógico, vale explicitar que, ao contrário do grupo focal, que segue uma lógica monológica (participantes conversam entre si, mas também constantemente com o moderador), no GD a lógica exclusivamente é dialógica - os participantes conversam exclusivamente entre si, construindo o discurso grupal. Note-se que o papel do moderador/pesquisador é tornar-se invisível. Essa percepção foi construída pela pesquisadora a partir da observação e também da leitura da obra de Gutiérrez (2009). A dialogicidade pode ser também compreendida a partir de Alonso ao propor que a lógica dialógica da qual emana do grupo resulta do intercâmbio entre os atores, portanto o GD avança na busca de significados compartilhados pelos seus membros que se reconhecem em esquemas interpretativos na mesma elaboração de significados (Arboleda, 2008)

Há, portanto, como observamos até aqui, toda uma lógica interna que justifica uma maior abertura do GD no que tange à dinâmica grupal, quando comparada à tendência diretiva do focus group. Entretanto, cabe desde logo alertar que não há uma distinção entre GD e focus group que se possa justificar - tal como se vem mantendo de maneira equivocada - exclusivamente em virtude de dinâmicas de condução mais ou menos diretiva, como passaremos a explanar a seguir.

0 que se pode afirmar, de modo um pouco mais complexo, é que o GD constitui uma "situação discursiva aberta", contrária a qualquer "situação discursiva fechada" constitutiva do focus group, para usar os termos de Gutiérrez (2008). Cabe ressaltar que, no GD, a situação discursiva pode ser "aberta" (menor influência do moderador) ou também "dirigida” (maior influência do moderador). Explicando melhor, o moderador pode buscar promover o discurso livre e espontâneo, por meio da mínima intervenção, ou dirigi-lo. Porém, dirigir não significa fechar ou ordenar, mas sim orientar e canalizar o grupo, com o objetivo de evitar percursos improdutivos para o objetivo da pesquisa (Gutiérrez, 2008). Essa dupla possibilidade começa por desmitificar a equivocada utilização do grau de influência do moderador como diferenciação exclusiva entre as duas técnicas.

A própria situação discursiva, explica Gutiérrez (2008), é caracterizada, além de pelo grau de influência do moderador, também pela proximidade ou distância do grupo do efeito conversacional dialógico (no GD) ou monológico (no focus group). $\mathrm{Na}$ situação monológica, o significado do discurso grupal é substituído pela mera constatação de categorias e relações previamente estabelecidas. Cabe ainda dizer que, além de monológica, dependendo do grau de influência do moderador, a situação discursiva pode, na classificação de Gutiérrez, ser também de dois tipos: situação discursiva ordenada (menor influência do moderador) ou fechada (maior influência do moderador) - raciocínio que completa como, por meio de uma única tipologia, pode-se modificar o entendimento tradicional dessas técnicas. Entretanto, a fim de 
permitir uma compreensão mais ampla do leitor das inúmeras diferenciações, de várias ordens, que se pode estabelecer entre GD e focus group, elaboramos um amplo quadro comparativo-sintético, gerado a partir da análise da obra de vários autores (Quadro 1).

\section{Quadro 1. Comparação entre grupo de discussão e focus group}

\begin{tabular}{l}
\hline Grupo de discussão \\
\hline Autor principal: Ibáñez \\
\hline Posicionamento epistemológico: dialética-estrutural \\
\hline Aspiração à emancipação do grupo como sujeito, por meio da \\
vinculação com técnicas de socioanálise e psicanálise. \\
\hline Liberação do discurso e interpretação do grupo. \\
\hline Início a partir do sem sentido interpretado pelo grupo. \\
\hline Conversação: discussão em um acordo mútuo que comporta uma \\
construção conjunta de sentido. \\
\hline Aberto e flexível, permitindo mais abertura ao campo da observação. \\
Interessa a espontaneidade do grupo, pois se pretende dar a \\
oportunidade de que emerja o processo grupal de conversação que \\
dará lugar a uma posterior análise do discurso.
\end{tabular}

Processo sinérgico pleno: as pessoas trabalham juntas, e não separadas, na manutenção da conversação; processo de manutenção constante de cada individualidade por meio da própria ação coletiva.

Trabalha com resistências e impedimentos que sufocam ou encobrem o discurso.

Discurso grupal como intercâmbio verbal a produzir.

Abertura de espaços de continentes para "deixar falar" ao grupo.

Busca-se a assunção grupal da responsabilidade (tratando de evitar a dependência do moderador).

O moderador se assegura de que no grupo se produz uma única conversação.

O moderador suscita uma conversação mediante uma técnica aberta: a) incitando a que fale quem permanece em silêncio e a que deixe falar quem não se cala, e assim tratam de impor seu critério; b) repartindo o jogo, mas sem imprimir um ritmo determinado ao grupo; c) mantendo uma atitude de escuta e observação ativa.

O moderador da conta de sua estratégia para o tratamento dos objetivos. Não se constitui em algo fechado que há que seguir ao pé da letra.

O moderador trabalha com o sentido das ações técnicas (invisibilidade do moderador e sua dinâmica).

O moderador está por trás, deixando o grupo falar.

Reflexivo e crítico com a própria técnica e com o trabalho do moderador (importância da transferência).

\section{Focus group}

Autor principal: Merton

Posicionamento epistemológico: positivismo

Aproximação ao conhecimento do grupo como objeto, permitido pela vinculação com técnicas comportamentais e experimentais.

Submissão do discurso e das interpretações grupais.

Início a partir do pressuposto de um consenso discursivo prévio e aceitado.

Debate: discussão tanto organizada como dirigida a partir de experiências particulares.

Focalizado em aspectos concretos dos objetivos da pesquisa. Interessa a espontaneidade de quem participa, pois se atende mais ao processo interativo entre esses e às intervenções do moderador - debate que costuma ser submetido a uma análise de conteúdo contextualizado e não tanto de discurso.

Processo sinérgico condicionado: as pessoas trabalham tanto juntas quanto separadas com o moderador; suas intervenções e respostas a outros participantes constituem espelho de confrontação para cada um.

Trabalha com sugestões e proposta que ativam e acrescentam discurso.

Discurso grupal como produto ou dado a registrar.

Estabelecimento de conteúdos para "fazer falar" ao grupo.

Impõem-se a dependência do grupo ao moderador.

O papel do moderador se caracteriza pela diretividade.

As principais tarefas do moderador são: a) ser um motor do grupo; b) lançar perguntas ao grupo e algumas vezes oferecer-lhe respostas, desde a posição de liderança; c) controlar o grupo (decidindo assim quem, quanto e quando intervém) para que os participantes não deixem de abordar os temas que lhes propõem.

O moderador atende a uma discussão em forma de debate, incluindo tanto perguntas (em ordem preestabelecida) como materiais de estímulo, técnicas projetivas, tendo em conta que durante a sessão dificilmente poderá omitir-se nenhum aspecto que previamente haja sido negociado com a demanda do estudo.

O moderador trabalha com as ações técnicas (visibilidade do moderador e sua dinâmica).

O moderador está pela frente, fazendo o grupo falar.

Reflexivo e crítico com as condições de observação e seus efeitos (importância da reatividade).

Fonte: Elaborado a partir de Sánchez-Pinilla e Legerén (2008); Domínguez e Davila (2008); Gutiérrez (2008, 2011); Colectivo IOE (2011). 
Para finalizar este capítulo, caberia ainda mencionar uma característica postulada por Ibáñez (2003) que diferencia o GD de qualquer outra técnica que utiliza grupos como instrumento de manipulação. Há no GD um sentido reflexivo que permite que a técnica retorne sobre ela mesma e leve em conta os efeitos que a técnica produz, interpreta Gutiérrez (2011). Surge nesse contexto a mensagem de Ibáñez (1979 como citado em Gutiérrez, 2011) bastante conhecida na pesquisa social espanhola, de que não se trata de prescrever como se faz tal coisa, mas sim as consequências de fazê-lo.

\section{DESENHO E FORMAÇÃO DO GRUPO}

Neste capítulo, discutiremos - além dos componentes principais do desenho dos grupos, a saber, o número total de grupos e as variáveis ou atributos que definem os participantes de cada grupo - também questões que envolvem a convocatória e o tempo da reunião.

Tal como em qualquer estratégia de pesquisa qualitativa, o desenho do GD é aberto e artesanal, ou, como mencionam Canales e Peinado (1994), consiste no momento mais arbitrário da pesquisa, uma vez que depende de decisões originárias da formação e da experiência do pesquisador. Em virtude dessa abertura e flexibilidade, Ibáñez (2010) não considera o desenho a parte mais importante da pesquisa, ainda que concorde tratar-se de um dispositivo que atravessa todo o processo.

Evidentemente que, seguindo a lógica da pesquisa qualitativa, a amostragem do GD - definição do número de grupos - não depende de critérios estatísticos, mas sim "estruturais" (ver, por exemplo: Canales \& Peinado, 1994; Cano \& Rubio, 2005; Colectivo IOE, 2010; Manrique \& Pineda, 2009;) e, em geral, trabalha-se com um número pequeno de grupos. A amostra estrutural não é um conceito de simples compreensão, pois envolve critérios de representação social e discursiva, além, é claro, dos objetivos do estudo. Para tomar os exemplos de Canales e Peinado (1994), buscam-se nessa definição: variáveis sócio demográficas (tais como sexo, idade, classe social, região, entre outras); relações ou tipos sociais (por exemplo, jovens ou adultos; jovens trabaIhadores ou estudantes; operários, classes médias etc.); e, como dissemos, outros atributos oriundos dos objetivos da pesquisa.

Em nossa experiência de observação prática, também evidenciamos a presença, por vezes, de outras variáveis estruturais, como a opção religiosa e hábitos referentes a diferentes redes televisivas ou jornais. Todas essas variáveis definidas durante o desenho são cruzadas, a fim de constituir os grupos. Não há regras predefinidas no que tange ao número de atributos, no entanto os autores são unânimes em alertar sobre a necessi- dade da busca de "saturação" do campo discursivo. Além disso, lembram Canales e Peinado (1994) que uma norma que precisa ser seguida é a de considerar a "homogeneidade" no interior dos grupos também com uma certa "heterogeneidade", a fim de buscar tanto a simetria quanto a diferença no processo discursivo. Cabe assinalar que uma "fórmula" para a obtenção desse equilíbrio reside em combinar a homogeneidade social e a heterogeneidade das variáveis relativas ao processo de investigação. Também no interior dos objetivos da pesquisa reside a resposta para a definição do número de grupos a desenhar, isto é, uma determinada população pode ser mais ou menos homogênea em relação ao tema estudado. Explicando melhor essas noções, a "homogeneidade", assim como a "heterogeneidade", referem-se às variáveis estruturais (características socioeconômicas, ideológicas, e outras ligadas especificamente aos objetivos da pesquisa) que devem ser observadas na composição dos grupos a fim de assegurar tanto a "simetria" quanto a "diferença” interna do discurso.

Em um conhecido estudo conduzido por Conde e Gabriel (2002) - La evolución de las representaciones sociales sobre la salud de las mujeres madrileñas 1993-2000 - os autores trabaIharam, em 2000, com mulheres de várias regiões espanholas com 10 GDs configurados a partir da seguinte tipologia com a seguinte heterogeneidade interna: 1) mulheres com noções biomédicas sobre saúde; 2) mulheres preocupadas com a sua saúde; 3) mulheres com noções holísticas; 4) mulheres com noções baseadas no equilíbrio pessoal; e 5) mulheres com noções baseadas no código de resistência. Essa tipologia norteadora do estudo qualitativo surgiu de um survey que havia sido realizado pelos autores, em 1993, com 1.299 mulheres de 18 anos ou mais, no qual foi utilizada análise de clusters. Obtida a tipologia quíntupla, o conjunto de 10 GDs foi inserido em um mapa com dois eixos localizadores do posicionamento de cada grupo em relação somente a dois critérios de homogeneidade: status e modernidade a que seus estilos de vida se referem. A partir daí, procedeu-se à análise do discurso dos grupos utilizando a metodologia proposta por Conde (2009 como citado em Godoi, Coelho, \& Serrano, 2014).

É importante mencionar ainda as duas principais regras constitutivas do grupo em si: a) o tamanho do grupo deve variar entre cinco e 10 participantes (Canales \& Peinado, 1994; Colectivo IOE, 2010; Ibáñez, 2010; Ortí, 1986); e b) os membros não devem conhecer-se previamente (Alonso, 1998; Canales \& Peinado, 1994). Esse último critério visa evitar que a intimidade prévia possa gerar inibição acerca de alguns temas, além do que, o grupo não pode preexistir à construção do texto (Alonso, 1998; Ortí, 1986). Quanto à maioria dos autores ser demasiadamente prescritiva acerca do limite de participantes de um grupo, 
a explicação oferecida é originária da obra de Ibáñez (2003). Entende-se que dois ou três não constituem um grupo, mas sim uma relação embrionária e especular; somente a partir de cinco os canais de comunicação superariam o número de participantes tornando possível a reunião grupal (Canales \& Peinado, 1994). A recomendação geral de duração da reunião reside entre uma e duas horas. Entretanto, a nossa observação prática - retomando aqui a questão da possibilidade de abertura e flexibilidade do desenho - é de que, por questões de viabilidade e experiência do investigador, eventualmente, o grupo pode não seguir essas recomendações tão rígidas acerca do número de participantes e da durabilidade.

Definidas as variáveis constitutivas dos grupos e seu número de componentes, os participantes são selecionados e convocados de maneira anônima. No campo da sociologia e dos estudos de mercado, costuma-se trabalhar com contactadores profissionais, uma vez que esse contato precisa ser realizado por alguém diferente do pesquisador-moderador. Por certo que estamos falando de um nível societal de análise mais amplo do que o organizacional e que, no campo dos estudos organizacionais acadêmicos, tal regra precisaria ser adaptada. Ortí (1986) também recomenda que os participantes saibam o mínimo possível sobre os objetivos da pesquisa. Nesse momento da convocatória já são estabelecidos os acordos sobre a confidencialidade e o anonimato, e, por certo, os dias, lugar e horário da reunião (Manrique \& Pineda, 2009).

Muitas vezes não se realiza apenas uma reunião com cada grupo. Essa decisão inerente ao desenho e à experiência do pesquisador é também dependente do nível de saturação. No entanto, Ortí (1986) sugere que se definam, em princípio, duas reuniões por variável do estudo. Esse número é hipotético, pois depende do surgimento de redundâncias ou, ao contrário, de fragmentações, novas ideias e discursos que impedem atingir o difícil consenso dentro dos grupos.

\section{O PAPEL DO MODERADOR}

O tema da pesquisa, objeto da reunião do grupo, só adquire sentido a partir do moderador, uma vez que é este quem o apresenta (Callejo, 2001). O moderador, em geral, é o próprio pesquisador, no entanto a literatura indica que pode ser também alguma pessoa que conheça o que se busca na pesquisa. Porém, existe unanimidade em torno do pensamento de Ibáñez (2003) de que deva sempre se tratar de uma pessoa desconhecida dos participantes, pois, do contrário, o grupo já iniciaria com uma relação maior de confiança, o que não interessa a essa prática. Tampouco o moderador há que falar com os participantes antes do início da reunião. Tanto autores clássicos do GD, como Ortí (1986), quanto a observação prática sugerem que, durante a chegada de cada participante, nos momentos que antecedem o início da reunião, quem permanece junto às pessoas é alguém alheio à investigação.

Observamos também que, após agradecer a presença dos participantes e iniciar a reunião, apresentando de maneira genérica seus objetivos, o moderador conduz as seguintes falas: explicação da dinâmica da reunião; advertência de que os participantes é que estruturam o tema a partir de seus valores, crenças, opiniões e experiências. Essa abordagem inicial é confirmada na literatura por Ortí (1986) e; Gutiérrez (1999), que acrescentam ainda a necessidade de alertar o grupo de que seu papel como moderador é apenas conduzir tecnicamente a reunião.

Na prática, os estilos de moderação variam bastante entre os pesquisadores e são dependentes, por certo, dos objetivos da reunião. Apresentam-se, por exemplo, de maneira mais aberta quando se trata de buscar representações sociais e discursivas, e um pouco mais diretivas diante da necessidade do momento da pesquisa de vincular os participantes diretamente ao objeto. Tais estilos, quase invariavelmente, também percorrem um eixo de diretividade do início ao final da reunião, com aumento a partir da segunda metade. No entanto, no GD trata-se sempre de uma situação discursiva “dialógica aberta ou dirigida”, nunca "fechada ou ordenada".

Na dinâmica de articulação entre o moderador e a conversação grupal, o primeiro, ainda que constitua a pessoa que abre os caminhos para as falas, define as pautas e, como concebe Callejo (2001), converte-se no elo de circulação do discurso, abstém-se totalmente de emitir a sua opinião e participar do processo discursivo. Essa advertência de inúmeros autores - por exemplo, Ortí (1986); Callejo (2001); Manrique e Piñeda (2009) - que impede o moderador de fazer parte do grupo e, principalmente, emitir juízos de valor verbais ou não verbais, é de extrema importância e exige tempo de aprendizagem e treinamento por parte do pesquisador.

0 que cabe, sim, ao moderador é devolver ao grupo seu discurso, tal como em uma função de "espelho", para utilizar a expressão de Callejo (2002a). Explicando melhor a "função espelho" do moderador: em oposição ao grupo focal, não cabe ao moderador emitir intervenções alheias ao discurso do grupo, direcionado as falas, tampouco assumir uma postura cúmpliceconfirmatória ou repressora da intervenção de algum participante. Suas intervenções, após um diálogo sequencial, no entender de Ibáñez (2010), devem espelhar apenas o conteúdo manifesto ou latente do diálogo do grupo. À devolução ao grupo do conteúdo latente, observamos, na experiência prática, produz um efeito interpretativo e reflexivo, melhor seria dizer, de ressignificação simbólica ao grupo. 
Há também, na recomendação de Ortí (1986), três casos em que deve o moderador intervir: quando o grupo derive a outro tema; em uma situação de agitação, isto é, alteração entre os participantes; e quando um líder, ou pessoa que tente ocupar qualquer situação hierárquica, monopolize a situação. Sobre essa última situação, que na prática da pesquisa se verifica constantemente, Canales e Peinado (1994) ponderam de que não se trata de calar totalmente o líder, mas de controlá-lo para que o grupo continue a existir. Para controlar situações como essa é que o líder constitui e deve manter sua autoridade no grupo no qual opera como motor.

Uma vez que ao líder não é permitido opinar e participar diretamente da conversação, um dos principais momentos de angústia, especialmente dos iniciantes na técnica, diz respeito ao silêncio (Canales \& Peinado, 1994; Gutiérrez, 1999, 2001). Tais autores, como pesquisadores experientes, orientam que há que se suportar o silêncio e deixar que a angústia seja transferida ao grupo, a quem cabe romper o silêncio.

Acerca dos invitáveis conflitos emergentes no grupo, Callejo (1998) recomenda que não há que se ter urgência em controlá-los, uma vez que se trata quase sempre de algo positivo, que só exige atuação do moderador quando ameaçam o grupo e provocam a iminência de sua ruptura. Ibáñez (2003) também alerta que não cabe ao moderador corresponder à demanda grupal ou ajudar o grupo a compreender a ausência de sentido de sua demanda. A experiência de observação prática mostra que os conflitos quase invariavelmente surgem de maneira espontânea - uma vez que o grupo é a versão micro da sociedade - e que a habilidade de colocar o grupo contra si mesmo, apontar as contradições e conduzir a uma finalização consensual é uma arte.

Um dos sintomas de que uma reunião de grupo terminou, auxilia Callejo (2001), é quando, na percepção do moderador, os participantes se converteram em grupo, isto é, começam a ter consciência de grupo. 0 autor acrescenta que, nesse momento de saída do discurso grupal, o moderador responsabiliza-se por sintetizar a produção discursiva, apontando as relações de coerência, incoerência e conexões de sentido entre os enunciados.

\section{A DINÂMICA DA REUNIÃO}

Provocaremos neste capítulo um certo descentramento do papel do moderador, seu estilo de condução e principais funções no grupo, tal como abordado no capítulo anterior, para focalizar a dinâmica da reunião em si, com ênfase em suas etapas, acontecimentos e materiais auxiliares, ainda que estejamos conscientes de que a divisão elegida entre os conteúdos dos dois capítulos tenha somente finalidade de organização didática, uma vez que a condução da dinâmica da reunião está intrinsecamente relacionada ao papel do moderador.

Iniciaremos por abordar um instrumento que costuma ser controverso entre os pesquisadores que utilizam diferentes técnicas de pesquisa qualitativa. Trata-se da necessidade de lançar mão de um roteiro que auxilie a condução da coleta do material discursivo. Entre os autores favoráveis à utilização de um roteiro na condução do grupo, encontram-se Gutiérrez (2001); Ibáñez (2003); Sánchez-Pinilha e Legerén (2008). O roteiro constitui um instrumento que, em geral, contém uma ordenação temática de tópicos originários dos objetivos da investigação, descreve Gutiérrez (2001). 0 autor acrescenta que se trata de uma listagem de questões a propor que sejam discutidas pelo grupo. Sugere, ainda, que, em sua estrutura, as temáticas sejam dispostas de modo sequencial, isto é, dispostas em um eixo de continuidade do mais amplo e vago ao mais concreto e preciso.

Ao passo que Gutiérrez (2008) insiste nas vantagens do roteiro, como o fato de permitir ao moderador maior tranquilidade no percurso da reunião, o próprio autor adverte que em nenhum momento pode-se impor ao grupo todos os temas e, tampouco, a sequência em que aparecem no roteiro. Apresentando uma postura mais receosa em relação à necessidade de roteiro estruturado, Callejo (2001) considera que um roteiro de perguntas condiciona o moderador e acaba por eliminar a flexibilidade e a possibilidade de adaptação da técnica ao grupo. 0 autor sugere então duas possibilidades: que se utilize apenas uma lista de temas a serem abordados na reunião a serem apresentados no momento em que pareça mais adequado; ou que o pesquisador conduza a reunião prescindindo do roteiro e somente com os objetivos da pesquisa e da sessão em mente. A oportunidade de vivência prática permite observar que essas considerações de Callejo (2001) são as que transpassam a experiência cotidiana dos pesquisadores, no entanto, por certo que há que se considerar a variação existente entre estilos de condução a dependência do tipo de objetivos da pesquisa. Um fato interessante observado na condução dessa prática foi a marcação, por vezes, na lista geral de tópicos, de alguma temporalização entre os temas, a fim de garantir a consecução da reunião.

Apresenta-se a seguir uma modalidade de roteiro para condução de um tema de mercado proposto por Gutiérrez (2008):

- Introdução.

- Breve reconstrução de hábitos e estilos de vida sobre a compra e a preparação de comidas.

- Uso e atitudes sobre a conservação de alimentos em geral e, em particular, sobre a conservação de alimentos em geral, em lata, congelados, defumados, desidratados etc. 
- Atitudes e conceitos associados ao conceito pasteurizado.

- Reações e valorações espontâneas associadas a proposta de "alimentos pasteurizados".

- Apresentação do produto e reações suscitadas (sabor, qualidade e usos concretos etc.).

- $\quad$ Atitudes do invólucro onde se apresenta o produto pasteurizado.

- Valoração de outras variáveis: preço; localização da compra etc.

- $\quad$ Fechamento do grupo.

Decidida essa questão, a dinâmica da reunião inicia com a apresentação, por parte do pesquisador, da proposta inicial do tema. Na concepção de Ibáñez (2010), essa proposição pode ser realizada de maneira denotada ou conotada. Para utilizar os exemplos do autor, a proposta denotada pode ocorrer de duas formas: no nível do tema (ex.: cerveja para discutir cerveja); ou no nível superior (ex.: bebidas para discutir cerveja). Já a provocação conotada, explica o autor, pode ser propondo um tema que leve ao tema, seja por metáfora ou por metonímia. 0 processo de observação da condução de grupos indica como opção mais frequente dos pesquisadores a denotada superior (ex.: da nossa observação: televisão para discutir a percepção da imagem sobre a cadeia $x$ de televisão).

Nessa intervenção inicial, portanto, a enunciação do tema por parte do pesquisador, como dissemos, em geral ocorre de modo bastante geral, apenas indicando os limites da discussão, sem fechar o conteúdo ou impor um sentido a priori. Essa abordagem, que, a uma primeira vista, pode parecer deixar o grupo sem rumo, quando observada na realidade empírica, o que ocorre é que o sentido, a delimitação e o foco logo emergem da própria dinâmica do grupo. Além de concordarem com a generalidade da primeira enunciação, Canales e Peinado (1994) levam em conta ainda outros dois aspectos que fazem parte da primeira fala do moderador: o enquadre técnico a ser realizado de um modo completo, conciso; e a necessidade de um enfático agradecimento aos participantes pela participação, evidenciando a importância de suas opiniões para o desenvolvimento da pesquisa. Esse último aspecto, na concepção dos autores, objetiva promover a inflagem narcisista do grupo capaz de motivar a discussão inicial. Há outro dispositivo inerente ao processo grupal que suscita o desejo de discutir o tema, postulado por Ibáñez - em virtude da influência psicanalítica que traspassa sua obra - denominado transferência/contratransferência. 0 autor explica que, desde a entrada do moderador em sala, produz-se, entre ele e o grupo, uma rede de cumplicidade ou de enfrentamentos implícitos que necessita ser manejada favoravelmente à discussão.
As intervenções subsequentes do moderador podem ocorrer, por vezes, quando se trata de pesquisadores iniciantes, de três formas: repressiva, cúmplice ou “de espelho” (Ibáñez, 2010). Entretanto, Ibáñez adverte que somente essa terceira posição é a correta e que pode surgir de duas maneiras: por meio da devolução ao grupo do desejo manifesto; ou por meio da devolução, ao grupo de um desejo latente que fora interpretado pelo pesquisador. Observamos que, na maioria das situações práticas, há um predomínio da devolução apenas do desejo manifesto, ficando a interpretação somente para o momento da análise do discurso grupal.

A sequência da dinâmica grupal é exposta por Manrique e Pineda (2009) de maneira sucinta e útil, uma vez que também fora por nós observada nas situações concretas. Num primeiro momento, são estabelecidos os detonadores - termo utilizado para designar os temas gerais, já mencionados neste capítulo, que definem a linha condutora da reunião. Em seguida, deriva-se aos subtemas específicos, motivando a expressão de ideias, sentimentos, atitudes e experiências dos participantes. Por fim, os subtemas específicos são lançados ao grupo sob a forma da devolução de expressões, frases ou ideias curtas a fim de discutilos até o esgotamento.

A complexidade da dinâmica da reunião envolveria ainda abordar diversos outros aspectos, tais como a importância da presença física e, por vezes, silenciosa do moderador, lembrada por Gutiérrez (1999); a prática de utilização das mãos para suspender intervenções, observada na experiência prática e geradora de excelentes resultados. No entanto, para finalizar o capítulo, optamos por analisar a situação geral de ansiedade que constitui a reunião e da qual o moderador precisa dar conta e manejar tecnicamente. No entender de Gutiérrez (1999), trata-se da questão mais difícil de pôr em prática. Em síntese, o autor considera que a ansiedade por parte do grupo é originária do fato de as pessoas reunidas não se conhecerem, tampouco conhecerem a situação grupal e sua proposta. Diante de tal emoção, cabe ao moderador dissipá-la, sem mostrar confusão, e canalizá-la a fim de motivar e criar interesse para a realização do trabalho.

\section{CONSIDERAÇÕES FINAIS}

A origem da técnica e prática do GD é atribuída à obra Más allá de la sociologia. El grupo de discusión: teoría y crítica, escrita por Jesús Ibáñez, em 1979. A partir desse marco, como narra Gutiérrez, cada vez mais a versão espanhola vem sendo considerada uma técnica radicalmente distinta do grupo focal. Entretanto, fora da Espanha e da maior parte dos países da América Latina, 
o GD permanece ou desconhecido ou tratado quase como sinônimo do focus group.

Tal como trabalhamos longamente no capítulo segundo deste ensaio, não pretendemos com a descrição e análise dos elementos do GD que, em algum momento, tal narrativa seja tomada como receituário formal ou fechado. A aparência prescritiva acaba por tornar-se inevitável na maior parte dos textos teórico-metodológicos; ainda assim procuramos mesclar a experiência dos metodólogos estudados com aquela dos pesquisadores contida nos relatórios de investigação utilizados e, principalmente, com a peculiaridade da oportunidade de vivência prática em um instituto de pesquisa espanhol. As seguintes oportunidades de experiência: observação de vídeos de GD que faziam parte do acervo do CIMOP; observação, juntamente com o cliente, de outros grupos diretamente no momento em que ocorriam; e de aprendizagem tácita com os pesquisadores que utilizam a técnica desde suas origens - constituíram a principal fonte motivadora da sistematização aqui presente. Cabe ainda aqui dizer tem este artigo ênfase teórica, metodológica e didática por tratar-se dos resultados dos principais estudos em obras, artigo, relatórios de pesquisa (Conde, 1996, 1999, 2002; Conde \& Gabriel, 2002) e vídeos disponíveis no CIMOP (1997a, 1997b, 2009, 2010). Os comentários pessoais que viabilizaram a estrutura de ensaio referem-se exclusivamente à prática de observação das reuniões conduzidas dentro do instituto e ainda não de uma prática já consolidada de pesquisa empírica da pesquisadora que somente agora conclui seu primeiro projeto de investigação sobre GD, bem como sua primeira orientação de tese baseada nessa prática.

0 aparente caráter prescritivo do texto justifica-se também por ser o GD, como a concebe Ibáñez (2003) uma técnica que se ocupa dela mesma, paradoxalmente, preocupada principalmente com o que faz ou com o que deixa de fazer a própria técnica. Ainda que não tenha sido a proposta e o espaço do artigo trabalhar com a teoria do conhecimento subjacente à técnica, cabe sempre lembrar que uma técnica de pesquisa sem uma epistemologia que a sustente arrisca-se a incorrer num conjunto de procedimentos vazios. Por ser o primeiro artigo de que temos conhecimento sobre GD no campo dos estudos das organizações, optamos por essa delimitação de trabalhar com a explicitação da origem, o que é e o que não é um GD. Nosso objetivo final consistiu em, por um lado, alertar os pesquisadores e desmitificar a confusa distinção entre o GD e outras práticas grupais de pesquisa qualitativa e, por outro, instrumentalizar os pesquisadores da área a sua utilização e os cuidados teóricos e experiências prévios necessários. Por certo que a experiência anterior do pesquisador com outras técnicas e estratégias de pesquisa qualitativa e análise do discurso são os cuidados-chave que permitirão manejar os diversos imponderáveis que surgem no momento da condução de um grupo.

Uma das questões menos discutidas - e mais relevantes - é o papel que desempenha o comportamento do investigador na aplicação dos métodos e técnicas de investigação (Gutiérrez, 2008). 0 descuido deixa sem reflexão teórica e/ou prática aspectos que costumam passar inadvertidos, porém que têm enorme relevância para a solidificação de todo o processo de investigação (Gutiérrez, 2008). Uma das ferramentas que podem ajudar no autocontrole do papel do mediador/pesquisador é a nota de campo (descritas em Godoi, Coelho \& Serrano, 2014). Esse instrumento, realizado após cada reunião de grupo serve para que o pesquisador descreva o funcionamento do roteiro, as primeiras impressões e intuições, e, principalmente, analise o seu papel como moderador. Esses comportamentos em nenhum caso solucionarão os erros e defeitos que se tenham produzido na coleta de dados.

Além dos descuidos apontados, ainda outros foram observados nas práticas iniciais da pesquisadora e em uma prática iniciada em disciplina eletiva de stricto sensu - análise qualitativa de dados, ministrada em formato de oficina: a) o hábito do moderador de, em sua prática de pesquisa, trabalhar com grupo focal pode dificultar a postura em realizar GD, logo, o pesquisador precisa ser treinado sobre distinções; b) insegurança do pesquisador iniciante geradora de um guia “estruturado", em vez de um simples e aberto plano de reunião - tal como observávamos os pesquisadores experientes utilizarem na Espanha; c) a possível dificuldade do moderador em sustentar o silêncio no grupo - na maior parte das vezes - ressignificador de sentidos no grupo; d) a tendência do moderador em dirigir o significado e intervir com interpretações que não foram ditas pelos membros do grupo.

Além da necessidade de formação teórico-metodológica do pesquisador que, pela primeira vez, utiliza a prática do GD, um dos paradoxos que, por certo, será encontrado diz respeito à necessidade do moderador de alternar, durante a sessão ou de uma sessão para a outra, posturas mais ou menos ativas. É sabido, conforme discutido no capítulo referente ao papel do moderador, que o grau de atividade da postura no interior do grupo não é suficiente para caracterizar o diferencial dessa prática em relação a outros modelos grupais. É permitido ao moderador iniciar uma sessão com uma introdução denotativa e uma postura passiva e assim prosseguir por toda a sessão, permanecendo "invisível" e deixando falar o grupo. Esse modelo é o que melhor possibilita a construção do discurso grupal. Paradoxalmente, pode ocorrer que, a partir da segunda metade da reunião, com dificuldades de atingir o consenso grupal, o moderador precise lançar mão seja de um roteiro mais sistematizado, seja de material auxiliar, capaz de induzir a fala e até mesmo o conflito 
- elemento profundamente privilegiado no interior de grupos. A percepção do tipo de moderação a utilizar e da alternância de sua postura, por certo, é construída com o tempo de experiência do pesquisador. Além do conflito, da censura estrutural provocada por um possível líder que faz o grupo calar, o pesquisador precisa estar preparado para as mais intempestivas situações que normalmente ocorrem na dinâmica das sessões.

Quanto aos paradoxos observados no grupo de participantes, um dos mais significativos diz respeito ao silêncio que pode ocorrer por parte de alguns membros, ainda que contactados de maneira voluntária e sabedores do recebimento de um brinde ao final da participação. Em uma experiência mais profunda que presenciamos com seis grupos de mulheres no Brasil, vimos o próprio grupo dirigir-se à pessoa que se cala. Entretanto, em outros grupos comandados por pesquisadores mais experientes em institutos em que, inclusive, havia brindes mais significativos, pessoas que permaneceram caladas durante toda a reunião não foram solicitadas a falar. Alguns temas são realmente considerados tabus ou traumáticos para algumas pessoas e, tal como afirma Gutiérrez (2008), os silêncios e as rupturas bruscas são partes das manifestações discursivas do grupo, porém produzem ao pesquisador sensações desagradáveis e desconcertantes acompanhadas da tentação urgente de assumir a fala e continuar ele próprio a conversação. Com a experiência, a tendência é aprender a lidar com a relevância do silêncio dos participantes.

Gutiérrez (2008) complementa ainda acerca de outros imponderáveis técnicos referentes aos participantes que podem tornar o grupo "defeituoso": terem sido contactadas pessoas que não pertencem às características homogêneas que compõem determinado grupo; indivíduos que de alguma forma se conheçam entre si; ou, ainda, que sejam especialistas nas questões que serão tratadas. Na experiência observada pela pesquisadora no instituto de especialistas, uma ou outra amostra foi considerada “queimada" por algum desses motivos. 0 grupo em questão foi realizado, porém não foi considerado para o projeto mais amplo.

Por fim, cabe dizer que as práticas de utilização do GD não se restringem mais ao campo dos estudos de consumo onde tiveram seu início, mas estendem-se também às áreas de sociologia, política, movimentos sociais, educação, saúde, entre outras. Torna-se importante refletir por que nos estudos organizacionais - campo tão próximo tanto da sociologia quanto dos estudos de consumo - mantém-se ainda alheio a sua existência e restrito ao uso de escassas técnicas de pesquisa qualitativa. Atualmente, estamos trabalhando com práticas sociológicas, ligadas aos estudos organizacionais, quais sejam, consumo da beleza e consumo da música (festivais de música eletrônica). As áreas da sociologia do consumo, bem como dos estudos organizacionais como um todo, dos estudos de gênero e do comportamento humano, são âmbitos propícios para o início da demarcação das práticas grupais de metodologia de pesquisa mais próxima da administração. Cabe ressaltar que a motivação deste ensaio emergiu quando a autora sentiu necessidade de elaborar uma narrativa completa de seus estudos em obras, artigos e relatórios de pesquisa material que em grande parte não teria acesso estando no Brasil, com dupla finalidade: nortear a prática de pesquisadores e estudantes interessados e em fase de entrada no campo, apresentar aos pesquisadores e professores brasileiros de metodologia uma nova possibilidade de prática de pesquisa qualitativa, desvinculada da epistemologia neopositivista como o grupo focal. Por esse motivo, a finalidade central deste texto não foi discorrer sobre exemplos práticos que somente agora estão sendo concluídos nos estudos organizacionais brasileiros.

\section{REFERÊNCIAS}

Alonso, L. H. (1998). La mirada cualitativa en sociologia. Madrid: Fundamentos.

Arboleda, Luz M. (2008). El grupo de discusión como aproximación metodológica en investigaciones cualitativas. Revista Facultad Nacional de Salud Pública, 26(1), 69-77.

Anzieu, D. (1986). El grupo y el inconsciente. Madrid: Biblioteca Nueva.

Callejo, J. (1998). Articulación de perspectivas metodológicas: Posibilidades del grupo de discusión para una sociedad reflexiva. Papers-Revista de Sociologia, (56), 31-55.

Callejo, J. (2001). El grupo de discusión: Introducción a una práctica de investigación. Barcelona: Editorial Ariel.Callejo, J. (2002a). Grupo de discusión: La apertura incoherente. Estudios de Sociolingüística, 3(1), 91-109.

Callejo, J. C. (2002b). Observación, entrevista y grupo de discusión: El silencio de tres prácticas de investigación. Revista Española de Salud Pública, 76(5), 409-422.

Canales, M., \& Peinado, A. (1994). Grupo de discusión. J. M. Delgado, \& J. Gutiérrez (Coord.). Métodos y técnicas de investigación en ciencias sociales. Madrid: Editorial Sintesis.

Cano, M. S., \& Rubio, J. L. M. (2005). Una propuesta de evaluación de la calidad universitaria desde la perspectiva del grupo de discusión. Circunstancia, 3(8), 44-66.

Comunicación, Imagen y Opinión Pública. (1997a). Las representaciones sociales sobre la salud de la población activa masculina de la Comunidad de Madrid. Madrid: Comunidad de Madrid. Consejería de Sanidad y Servicios Sociales.

Comunicación, Imagen y Opinión Pública. (1997b). Las representaciones sociales sobre la salud de los niños de 6 a 12 años de la comunidad de Madrid. Madrid: Comunidad de Madrid. Consejería de Sanidad y Servicios Sociales.

Comunicación, Imagen y Opinión Pública. (2009). Las actitudes de la población española sobre la atención a pacientes con enfermedad en fase terminal y la eutanasia. (Informe de resultados del estudio). Madrid: CIMOP. 
Comunicación, Imagen y Opinión Pública. (2010). El respeto a la diversidad sexual entre jóvenes y adolescentes. Una aproximación cualitativa. (Informe de investigación). Madrid: Gobierno de España, Ministerio de la Igualdad.

Colectivo IOE. (2010). ¿Para qué sirve el grupo de discusión? Una revisión crítica del uso de técnicas grupales en los estudios sobre migraciones. EMPIRIA: Revista de Metodología de Ciencias Sociales, (19), 73-99.

Colectivo IOE. (2011). La práctica del grupo de discusión en la investigación social (Oct-Nov). Madrid: Colectivo IOE.

Conde, F. (1996). La vivienda en Huelva (Informe de Investigación). Sevilla: Junta de Andalucía.

Conde, F. (1999). Los hijos de la desregulación: Jóvenes, usos y abusos en los consumos de drogas. Madrid: CREFAT-Cruz Roja.

Conde, F. (2002). La cuestión de la vivienda y los modelos de consumo. Estudios del Consumo, 55, 9-28.

Conde, F. (2008). Los grupos triangulares como "espacios transicionales" para la producción discursiva: Un estudo sobre la vivienda en Huelva. A. J. G. Lopez, \& A. S. Pascual (Coord.). Estrategias y praticas cualitativas de investigación social. (pp. 155-188). Madrid: Pearson Educación.

Conde, F. G. del A. (2009). Análisis sociológico del sistema de discursos (Cuadernos Metodológicos 43). Madrid: Centro de Investigaciones Sociológicas (CIS)

Conde, F., \& Gabriel, C. (2002). La evolución de las representaciones sociales sobre la salud de las mujeres madrileñas 1993-2000. Revista Española de Salud Pública, 76(75), 493-507.

Criado, E. M. (1997). El grupo de discusión como situación social. Revista Española de Investigación Social, 79(97), 81-112.

Domínguez, M., \& Davila, A. (2008). La práctica conversacional del grupo de discusión: Jóvenes, ciudadanía y nuevos derechos. A. Gordo, \& A. Serrano (Coord.). Estrategias y prácticas cualitativas de investigación social. Madrid: Pearson Educación.

Godoi, C. K., \& Coelho, A. L. A. L. (2011). Análise sociológica do discurso: Aproximação dos elementos epistemológicos, metodológicos e técnicos ao campo organizacional. Anais do 350 Encontro Nacional da Associação Nacional de Pós-Graduação e Pesquisa em Administração, Rio de Janeiro.

Godoi, C. K., Coelho, A. L. D. A. L., \& Serrano, A. (2014). Elementos epistemológicos e metodológicos da Análise Sociológica do Discurso: Abrindo possibilidades para os estudos organizacionais. Organizações \& Sociedade, 21(70), 509-535.

Gutiérrez, J. (1999). Consignas para el despegue de un grupo de discusión: Un modelo de presentación. EMPIRIA: Revista de Metodología de Ciencias Sociales, (2), 153-166.

Gutiérrez, J. (2001). Elementos no-técnicos para la condución de un grupo de discusión. EMPIRIA: Revista de Metodología de Ciencias Sociales, (4), 121-144.

Gutiérrez, J. (2008). Dinámica del grupo de discusión. Madrid: Centro de Investigaciones Sociológicas.
Gutiérrez, J. (2009). Técnicas grupales. J. Callejo, C. V. Cid, J. Gutiérrez, \& A. V. Rojas. Técnicas grupales en Introducción a las técnicas de investigación social. Madrid: Ed. Ramón Areces.

Gutiérrez, J. (2011). Grupo de discusión: ¿Prolongación, variación o ruptura con el focus group? Cinta Moebio, 41, 105-122.

Ibáñez, J. (2003). Más allá de la sociología. El grupo de discusión: Teoría y crítica (5rd ed.). Madrid: Sieglo Veintiuno Editores.

Ibáñez, J. (2010). Como se realiza una investigación mediante grupo de discusión? M. G. Ferrando, J. Ibáñez, \& F. Alvira, El análisis de la realidad social: Métodos y técnicas de investigación. (3rd ed.). Madrid: Alianza Editorial.

Lapassade, G. (Org.). (1989). Grupos, organizações e instituições. (3a ed.). Rio de Janeiro: Francisco Alves.

Lucas, A., \& Ortí, A. (1995). Génesis y desarrollo de la práctica de grupo de discusión: Fundamentación metodológica de la investigación social cualitativa. Investigación y Marketing, 47, 6- 9.

Manrique, A. M. M., \& Pineda, J. M. M. (2009). La técnica de grupo de discusión en la investigación cualitativa. Aportaciones para el análisis de los procesos de interacción. Revista Iberoamericana de Educación, 49(3), 1-7.

Merton, R. K., Fiske, M., \& Kendall, P. L. (1990). The focused interview: A manual of problems and procedures (2rd ed.). New York: Free Press.

Morgan, D. L. (1996). Focus groups. Annual Review Sociology, 22, 129152. doi:10.1146/annurev.soc.22.1.129

Mudança de imagem de uma rede de TV. (2013). Madrid: CIMOP. 119 min [vídeo].

Mudança na forma de consumo mediante as novas tecnologias. (2010). Madrid: CIMOP. 98 min [vídeo].

Ortí, A. (1986). La apertura y el enfoque cualitativo o estructural: La entrevista abierta semidirectiva y la discusión de grupo. M. García, J. Ibáñez, \& F. Alvira, (Eds.). El análisis de la realidad social: Métodos y técnicas de investigación. Madrid: Alianza.

Percepção dos empresários sobre o fenômeno da imigração. (2010). Madrid: CIMOP. 102 min [vídeo].

Qualidade de vida de cuidadores de pacientes terminais. (2003). Madrid: CIMOP. 92 min [vídeo].

Qualidade de vida de mulheres imigrantes na Espanha. (2011). Madrid: CIMOP. 111 min [vídeo].

Sánchez-Pinilla, M. D., \& Legerén, A. D. (2008). La práctica conversacional de grupo de discusión: Jóvenes, ciudadanía y nuevos derechos. A. Gordo, \& A. Serrano (Coord.). Estrategias y prácticas cualitativas de investigación social. Madrid: Pearson Prentice Hall.

Santoro, P., Gabriel, C., \& Conde, F. (2010). El respeto a la diversidad sexual entre jóvenes y adolescentes. Una aproximación cualitativa (Informe de investigación). Madrid: Gobierno de España, Ministerio de la Igualdad. 